NBER WORKING PAPER SERIES

\title{
CREDIBLE COMMITMENT TO OPTIMAL ESCAPE FROM A LIQUIDITY TRAP: THE ROLE OF THE BALANCE SHEET OF AN INDEPENDENT CENTRAL BANK
}

\author{
Olivier Jeanne \\ Lars E.O. Svensson \\ Working Paper 10679 \\ http://www.nber.org/papers/w10679
NATIONAL BUREAU OF ECONOMIC RESEARCH
1050 Massachusetts Avenue
Cambridge, MA 02138
August 2004

Part of the work was done while Lars Svensson visited the IMF.s Research Department as a Visiting Scholar and the Bank of England as a Houblon-Norman Fellow. He is grateful to these institutions for their hospitality and stimulating environment. The paper bene.ted from comments received in seminars at Duke University, the European Central Bank, the Federal Reserve Bank of New York, Princeton University, the University of California at Berkeley, the University of Mainz, the University of North Carolina and the 2004 NBER Summer Institute. We thank Priyanka Malhotra for excellent research assistance. Expressed views and any errors are the authors.own responsibility. They do not necessarily re.ect the views of the IMF. The views expressed herein are those of the author(s) and not necessarily those of the National Bureau of Economic Research.

C2004 by Olivier Jeanne and Lars E.O. Svensson. All rights reserved. Short sections of text, not to exceed two paragraphs, may be quoted without explicit permission provided that full credit, including $\odot$ notice, is given to the source. 
Credible Commitment to Optimal Escape from a Liquidity Trap: The Role of the Balance Sheet of an Independent Central Bank

Olivier Jeanne and Lars E.O. Svensson

NBER Working Paper No. 10679

August 2004

JEL No. E52, F31, F41

\begin{abstract}
$\underline{\text { ABSTRACT }}$
An independent central bank can manage its balance sheet and its capital so as to commit itself to a depreciation of its currency and an exchange-rate peg. This way, the central bank can implement the optimal escape from a liquidity trap, which involves a commitment to higher future inflation. This commitment mechanism works even though, realistically, the central bank cannot commit itself to a particular future money supply. It supports the feasibility of Svensson's Foolproof Way to escape from a liquidity trap.
\end{abstract}

Olivier Jeanne

International Monetary Fund

Lars E.O. Svensson

Department of Economics

Fisher Hall

Princeton University

Princeton, NJ 08544-1021

and NBER

svensson@princeton.edu 


\section{Introduction}

In a liquidity trap, the nominal interest rate is zero, but the real interest rate is higher than optimal, due to private-sector expectations of low inflation or even deflation. It is well known since Krugman [12], that the optimal way to escape from a liquidity trap is to generate expectations of a higher future price level and thereby expectations of higher future inflation. This will lower the real interest rate and stimulate the economy out of the liquidity trap, even though the nominal interest rate is zero. The problem, also emphasized by Krugman [12], is how to make the higher future price level credible. A promise of a higher future price level may not be credible, since the central bank may renege on its promise in the future and achieve a lower price level than promised, so as to maintain low and stable inflation.

This paper shows that a central bank's realistic concerns about its balance sheet and capital creates a commitment mechanism, which allows the bank to commit to a higher future price level through a current currency depreciation and a commitment to maintaining a weaker currency in the future. This commitment mechanism provides support for the Foolproof Way to escape from a liquidity trap that has been suggested by Svensson [19] and [20]. ${ }^{1}$ The bank wishes to maintain its independence from the government. A negative capital would require a capital injection from the government and put the bank at the government's mercy. In order to avoid this, the bank never voluntarily allows its capital to fall below a certain minimum level. Because undoing the current currency depreciation by a future currency appreciation would imply a future capital loss on the bank's foreign-exchange reserves, a minimum capital level provides a lower bound on the future exchange rate (an upper bound on the future currency appreciation). By managing its capital such that the minimum capital level is reached for the exchange-rate level consistent with the desired higher future price level, the bank can commit itself to that higher future price level. Although we believe that foreign-exchange reserves provide the most relevant and realistic case, this commitment mechanism could potentially also arise for other assets on central-bank balance sheets, such as equity, property and indexed bonds-but not, as we shall see, for fixed-income securities nominated in the home currency.

Although several recent papers on liquidity traps and the experience of Japan have emphasized the credibility problem of committing to future inflation for a central bank with an established

\footnotetext{
1 The Foolproof Way consists of announcing and implementing (1) a target path for the domestic price-level, starting above the current price level by the "price gap" that the central bank wishes to undo, (2) a currency depreciation and a crawling peg to achieve the price-level target path, and (3) an exit strategy in the form of abandoning the peg and shifting to flexible inflation or price-level targeting once the price-level target path has been reached.
} 
low-inflation reputation (for instance, Krugman [12], Svensson [19]-[21], and Eggertsson [5]), this literature has not explicitly incorporated the specific balance-sheet concerns of independent central banks.

Eggertsson [5] models the role of the nominal liabilities of a combined government and central bank in providing incentives to future inflation that will reduce the real value of the public debt and, thereby, distortionary taxation. In a liquidity trap, accumulation of more nominal debt strengthens incentives to inflation in the future and increases current private-sector inflation expectations. One way to increase the nominal debt is by borrowing in order to accumulate foreign exchange. In Eggertsson's setup, and counter to the situation in many countries, including Japan, the central bank is not independent but controlled by the government.

Our setup differs from Eggertsson's in several respects. More realistically, the central bank is not subordinated to the fiscal authority, and monetary policy is not used to reduce the public debt and lower future taxation. Instead the central bank is independent and concerned about its capital solely in order to maintain its independence. It is not concerned about the balance sheet of the consolidated public sector but about capital losses on its foreign-exchange reserves. Furthermore, it is indifferent to such capital losses as long as they do not lead to capital below the minimum level.

For both Krugman [12] and Eggertsson [5], central-bank independence and a lack of coordination of monetary and fiscal policy imply a problem and a barrier to the escape from a liquidity trap. In our paper, central-bank independence, together with balance-sheet concerns, provide the solution to this problem.

The balance-sheet concerns of central bankers is an area of research that has been left largely unexplored in the literature on monetary policy. However, as we show in section 4, there is a great deal of evidence that central bankers pay attention to the capital of the central bank because its level matters for the financial autonomy and the independence of the central bank. As more and more central banks become independent, it would seem important to understand better the channels by which the balance-sheet concerns of central bankers and monetary policy influence each other. As this paper illustrates, the balance-sheet concerns of central banks may have implications for the conduct of monetary policy that are non-trivial from an analytical point of view and relevant for real-world policy problems.

In the context of a liquidity trap, the balance-sheet concerns of central banks have been the subject of some informal discussion. Many commentators, for instance, Bernanke [3], have suggested 
that balance-sheet concerns of the Bank of Japan have been a barrier to more aggressive policies and that monetary and fiscal cooperation, including compensation for central-bank losses from risky open-market purchases, would contribute to Japan's escape from the liquidity trap.

In other contexts than a liquidity trap, more formal models of the balance-sheet concerns of central banks have been presented. Isard [11] presents a model of currency crises in which the central bank cares about the value of its foreign-exchange reserves. Sims [16] shows that a low level of capital may prevent a central bank from avoiding self-fulfilling hyperinflationary equilibria. In Sims's model, balance-sheet concerns are an impediment: they prevent the central banker from taking the right policy actions in a situation of economic distress. Sims argues that such situations will require a closer monetary and fiscal cooperation (a stronger "fiscal backing" of monetary policy), which the independence of the central bank is likely to make more difficult. ${ }^{2}$

Thus, according to the previous literature, balance-sheet concerns and central-bank independence may cause problems. In contrast, in this paper, we show that, in the context of a liquidity trap, balance-sheet concerns and central-bank independence may provide a solution, a commitment mechanism for optimal escape from a liquidity trap.

Section 2 lays out the model of the paper, shows how a liquidity trap can arise, and specifies the suboptimal policy under discretion and the optimal policy under commitment. Section 3 presents some evidence on the balance-sheet concerns of central banks. Section 4 shows how an independent central bank can commit itself to the optimal policy. Section 5 discusses some generalizations of our results. Section 6 provides some conclusions. An appendix includes some technical details.

\section{A simple open economy model of the liquidity trap}

We consider a small open economy, a simplified version of many current open-economy models, for instance, that in Svensson [21]. Households consume a traded good and a nontraded good. The nontraded good is produced with nontraded intermediate inputs whose nominal prices are set one period ahead by monopolistic producers. The central bank conducts flexible inflation targeting by minimizing a standard quadratic loss function of inflation and the output gap. We show that the economy may fall into a liquidity trap with excessively low output and inflation as a result of an

\footnotetext{
${ }^{2}$ Zhu [22] presents a model with central-bank balance-sheet concerns in the context of a liquidity trap. The balance-sheet concerns, in the form of an instrument rule with the instrument rate responding to both inflation and the central-bank's real capital, lead to indeterminacy of equilibrium and increase the risk of falling into a liquidity trap. He suggests automatic fiscal backing of monetary policy in order to avoid the indeterminacy.
} 
unanticipated fall in expected productivity growth and a related fall in the natural interest rate. ${ }^{3}$

\subsection{The structure of the economy}

Time is separated into discrete periods, $t=\ldots,-1,0,1, \ldots$ There is one traded good, the foreign good. The foreign-currency price of the good is unity in all periods. Let $S_{t}$ denote the exchange rate in period $t$, measured in home-currency units per foreign currency. The Law of One Price holds, so the home-currency price of the foreign good is simply equal to the exchange rate. A foreign-currency bond, with a constant continuously compounded interest rate, $r^{*}>0$, is the only traded asset.

The home country has a private sector, consisting of a household and firms, and a public sector, consisting of a central bank and a government. The household consumes the traded foreign good and the nontraded home good and supplies labor. The utility function of the household in period $t$ is

$$
\mathrm{E}_{t} \sum_{\tau=0}^{\infty} \delta^{\tau}\left[(1-\alpha) \ln C_{h, t+\tau}+\alpha \ln C_{f, t+\tau}+U\left(\frac{M_{t+\tau}}{P_{h, t+\tau}}\right)-N_{t+\tau}\right],
$$

where $\mathrm{E}_{t}$ denotes expectations conditional on information available in period $t, \delta \equiv e^{-r^{*}}$ is the discount factor, $C_{h t}$ denotes consumption of the home good in period $t, C_{f t}$ denotes consumption of the foreign good, $\alpha \in(0,1)$ denotes the consumption share of the foreign good, $M_{t}$ denotes the household's holding of home currency, $P_{h t}$ denotes the home-currency price of home goods, and $N_{t}$ denotes the supply of labor. The function $U\left(M_{t} / P_{h t}\right)$ represents the liquidity services of real money, which consist of time saved in the transactions of the home good. Real money is consequently measured in terms of the home good.

The liquidity-services function is continuous and continuously differentiable for $M_{t} / P_{h t}>0$ and has the additional properties

$$
\begin{gathered}
U\left(\frac{M_{t}}{P_{h t}}\right)<U_{0}, \quad U^{\prime}\left(\frac{M_{t}}{P_{h t}}\right)>0, \quad U^{\prime \prime}\left(\frac{M_{t}}{P_{h t}}\right)<0 \text { for } \frac{M_{t}}{P_{h t}}<e^{\mu} ; \\
U\left(\frac{M_{t}}{P_{h t}}\right)=U_{0} \text { for } \frac{M_{t}}{P_{h t}} \geq e^{\mu} ; \\
U^{\prime}\left(\frac{M_{t}}{P_{h t}}\right) \rightarrow \infty \text { for } \frac{M_{t}}{P_{h t}} \rightarrow 0 ;
\end{gathered}
$$

where $e^{\mu}>0$ is the satiation level of real money. That is, $U\left(M_{t} / P_{h t}\right)$ is increasing at a decreasing rate for $M_{t} / P_{h t}<e^{\mu}$ and has a maximum equal to $U_{0}$ for $M_{t} / P_{h t} \geq e^{\mu}$. There is a positive demand

\footnotetext{
${ }^{3}$ For simplicity, the liquidity trap is assumed to last one period, the same as the horizon of the nominal stickiness. So although the model is in infinite time, the analysis of the liquidity trap will involve two periods.
} 
Figure 2.1: The liquidity-services function

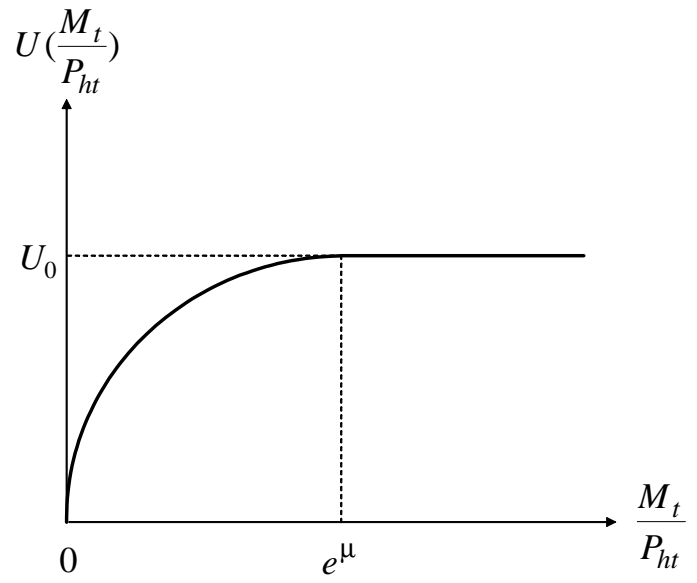

for real balances regardless of how high the home-currency interest rate is. The liquidity-services function is illustrated in figure 2.1.

The consumer price index $(\mathrm{CPI}), P_{t}$, will be given by

$$
P_{t}=P_{h t}^{1-\alpha} S_{t}^{\alpha},
$$

where we use the fact that the home-currency price of the foreign good is equal to the nominal exchange rate.

The nontraded home good is produced in two stages. In the final stage, final-good firms produce the output $Y_{t}$ of the home good with inputs of a continuum of nontraded intermediate goods, $Y_{t}(\iota)$, $\iota \in[0,1]$, according to the production function,

$$
Y_{t} \equiv\left[\int_{0}^{1} Y_{t}(\iota)^{1-1 / \xi} d \iota\right]^{\frac{1}{1-1 / \xi}},
$$

where $\xi>1$ denotes the elasticity of substitution between the intermediate inputs. The final-good firms operate under perfect competition and take the prices of the home good and intermediate inputs as given. The corresponding price index fulfills

$$
P_{h t}=\left[\int_{0}^{1} P_{h t}(\iota)^{1-\xi} d \iota\right]^{\frac{1}{1-\xi}},
$$

where $P_{h t}(\iota)$ denotes the home-currency price of intermediate good $\iota$. It follows that demand for intermediate good $\iota$ is given by

$$
Y_{t}(\iota)=Y_{t}\left(\frac{P_{h t}(\iota)}{P_{h t}}\right)^{-\xi}
$$


In the initial stage, each intermediate good $\iota$ is produced by a single firm $\iota$ with a technology that is linear in labor input with a country-wide exogenous stochastic productivity, $A_{t}$,

$$
Y_{t}(\iota)=A_{t} N_{t}(\iota)
$$

where $N_{t}(\iota)$ denotes labor input in the production of intermediate good $\iota$. There is hence a continuum of firms producing intermediate goods. Firm $\iota$ maximizes profits, subject to perfect competition in the labor market and monopolistic competition in the intermediate goods market (with the gross markup $\xi /(\xi-1)$ over marginal cost), and distributes the profits to the home household. Firm $\iota$ sets its price for period $t$ one period in advance, that is, in period $t-1$, so as to maximize the expected utility value of profits. Aggregate labor supply and demand will be given by

$$
N_{t} \equiv \int_{0}^{1} N_{t}(\iota) d \iota .
$$

The budget constraint in period $t$ for the home household is

$$
P_{h t} C_{h t}+S_{t} C_{f t}+M_{t}+B_{t}+S_{t} B_{t}^{*}=P_{h t} Y_{t}+M_{t-1}+e^{i_{t-1}} B_{t-1}+S_{t} e^{r^{*}} B_{t-1}^{*}+Z_{t}
$$

where $B_{t}$ denotes the number of home-currency one-period bonds held between periods $t$ and $t+1$, $i_{t}$ is the continuously compounded interest rate paid in period $t+1$ on those bonds, $B_{t}^{*} \gtrless 0$ denotes the number of foreign-currency one-period bonds held between period $t$ and period $t+1$ (positive if the household is a lender, negative if it is a borrower), and $Z_{t} \gtrless 0$ denotes the home-currency value of net transfers from the government. We use that the sum of total profits and wages received by the household will equal $P_{h t} Y_{t}$.

The budget constraint for the central bank is

$$
Z_{t}+S_{t} R_{t}=M_{t}-M_{t-1}+S_{t} e^{r^{*}} R_{t-1}
$$

where $Z_{t}$ is the home-currency value of the central bank's dividend paid to the government, $R_{t} \geq 0$ denotes the number of foreign-currency bonds held as foreign-exchange reserves between period $t$ and $t+1$, and $M_{t}-M_{t-1}$ is the change in the central bank's supply of home currency. In this simple model, the supply of home currency, the monetary base, and the stock of money are identical. For simplicity, we also assume that the only asset on the central bank's balance sheet is foreign-exchange reserves. As shown in appendix D, introducing domestic credit on the asset side of the central bank's balance sheet does not change our results. 
There is no government consumption. The government collects the dividend from the central bank and passes it on as a lumpsum transfer to the household. We assume that no home-currency bonds are held in the foreign country, and that the net supply of home-currency bonds is zero,

$$
B_{t}=0 \text {. }
$$

\subsection{Equilibrium relationships}

In equilibrium, consumption and production of the home good are equal,

$$
C_{h t}=Y_{t}
$$

Adding (2.5) and (2.6) and using (2.7) and (2.8), we can write the consolidated budget constraint for the home country in terms of the foreign good,

$$
C_{f t}+F_{t}=e^{r^{*}} F_{t-1}
$$

where

$$
F_{t} \equiv B_{t}^{*}+R_{t}
$$

denotes the home-country's net foreign assets.

The first-order condition for optimal intertemporal consumption of the foreign good will be

$$
e^{-r^{*}}=\frac{\delta \mathrm{E}_{t}\left(1 / C_{f, t+1}\right)}{1 / C_{f t}}
$$

(see appendix A for a derivation of the first-order conditions). Since $\delta=e^{-r^{*}}$, we realize from (2.9) and (2.10) that $C_{f t}$ and $F_{t}$ will be constant over time and fulfill

$$
\begin{aligned}
C_{f t} & =\left(e^{r^{*}}-1\right) F_{t-1} \equiv \bar{C}_{f} \\
F_{t} & =F_{t-1} .
\end{aligned}
$$

The current account is hence constant and unaffected by monetary policy. This property — which considerably simplifies the analysis - stems from the assumptions that utility is separable in consumption of home and foreign goods.

As shown in appendix B, firm $\iota$ 's optimal price is given by the first-order condition

$$
P_{h, t}(\iota)=\frac{\xi}{\xi-1} \mathrm{E}_{t-1} \frac{W_{t}}{A_{t}} .
$$

where $W_{t}$ is the nominal wage in period $t$. The price is simply set equal to the gross markup times the expected home-currency marginal cost. 
The first-order condition for the household's labor supply implies that the wage in home goods, $W_{t} / P_{h t}$, is equal to the marginal rate of substitution of home goods for labor,

$$
\frac{W_{t}}{P_{h t}}=\frac{1}{(1-\alpha) / C_{h t}}=\frac{Y_{t}}{1-\alpha}
$$

where we use (2.8). It follows from the two previous equations that

$$
P_{h t}(\iota)=P_{h t} \mathrm{E}_{t-1} \frac{Y_{t}}{\bar{Y}_{t}}
$$

where

$$
\bar{Y}_{t} \equiv \frac{\xi-1}{\xi}(1-\alpha) A_{t}
$$

is the flexprice level of output, the level that would prevail under flexible prices and constant money supply. ${ }^{4}$ Potential output is proportional to productivity.

Equation (2.14) shows how the decision of an individual price-setter $\iota$ depends on the prices set by the competitors as well as the expected ratio of actual to potential output. It says that an intermediate-good firm sets its price above (below) its competitors' if and only if it expects the ratio of actual output to potential output to be above (below) one. Since in equilibrium all intermediategood producers set their prices at the same level, the expected ratio of actual to potential output must be equal to one

$$
\mathrm{E}_{t-1} \frac{Y_{t}}{\bar{Y}_{t}}=1
$$

Actual output can deviate from potential output in the short run because of nominal stickiness. Given that the consumption of the traded good is constant, a change in the production (and consumption) of the nontraded good must be associated with a change in the real exchange rate. The real exchange rate, defined as the price of the traded foreign good in terms of the nontraded home good,

$$
Q_{t} \equiv \frac{S_{t}}{P_{h t}}
$$

will equal the marginal rate of substitution of the home good for the foreign good,

$$
Q_{t}=\frac{\alpha / C_{f t}}{(1-\alpha) / C_{h t}}=\frac{\alpha}{1-\alpha} \frac{Y_{t}}{\bar{C}_{f}}
$$

where we have used (2.8) and (2.11). The real exchange rate is proportional to output. We define the natural real exchange rate as the flexprice level, the level that would prevail under flexible

\footnotetext{
${ }^{4}$ One can show that the assumption of constant money supply is sufficient to ensure that no liquidity trap arises under flexible prices. An endogenous future money supply adjusted to maintaining low inflation may prevent an equilibrium and equality between output and potential output also under flexible prices; see footnote 14 .
} 
prices (and constant money supply),

$$
\bar{Q}_{t} \equiv \frac{\alpha}{1-\alpha} \frac{\bar{Y}_{t}}{\bar{C}_{f}} .
$$

We conclude this section with the equilibrium relationships for interest rates and money. The first-order condition for optimal intertemporal consumption of the home good is

$$
e^{-i_{t}}=\delta \mathrm{E}_{t} \frac{P_{h t} Y_{t}}{P_{h, t+1} Y_{t+1}},
$$

where we use (2.8) and that the marginal utility of nominal income is proportional to $1 /\left(P_{h t} Y_{t}\right)$. The real (CPI) interest rate, $r_{t}$, will fulfill

$$
e^{-r_{t}}=\delta \mathrm{E}_{t} \frac{P_{h t} Y_{t} / P_{t}}{P_{h, t+1} Y_{t+1} / P_{t+1}}=\delta \mathrm{E}_{t}\left(\frac{Y_{t}}{Y_{t+1}}\right)^{1-\alpha}
$$

where we have used (2.1), (2.17), and (2.18). The natural (CPI) interest rate, $\bar{r}_{t}$, is defined as the flexprice real (CPI) interest rate. By (2.21), it will fulfill

$$
e^{-\bar{r}_{t}}=\delta \mathrm{E}_{t}\left(\frac{\bar{Y}_{t}}{\bar{Y}_{t+1}}\right)^{1-\alpha}
$$

The home-currency interest rate fulfills the zero lower bound,

$$
i_{t} \geq 0
$$

Given the assumptions about the liquidity-services function, money demand can be written

$$
\begin{array}{ll}
\frac{M_{t}}{P_{h t}}=G\left(Y_{t}, i_{t}\right) & \left(i_{t}>0\right), \\
\frac{M_{t}}{P_{h t}} \geq e^{\mu} & \left(i_{t}=0\right)
\end{array}
$$

(see appendix A). Note that the satiation level, $e^{\mu}$, is independent of home output. The function $G\left(Y_{t}, i_{t}\right)$ has the properties

$$
\begin{gathered}
G\left(Y_{t}, i_{t}\right)<e^{\mu}, \frac{\partial G}{\partial Y_{t}}>0, \frac{\partial G}{\partial i_{t}}<0 \text { for } i_{t}>0 \\
G\left(Y_{t}, 0\right)=e^{\mu}
\end{gathered}
$$

\subsection{Productivity}

The dynamics of the economy is driven by the exogenous stochastic process for productivity. We specify this process in such a way that the economy may fall in a liquidity trap in period 1 and in that period only. This simplifies the analysis without substantial restriction of generality, since the 
policies that succeed in extracting the economy from a liquidity trap in period 1 can be implemented in other periods, too.

We assume that productivity is equal to a constant level $A$ up to period 1, and falls to a constant lower level $e^{-b} A$ from period 2 onwards $(b \geq 0)$. Denoting the $\log$ of variables by lower case, this assumption can be written

$$
\begin{array}{ll}
a_{t}=a & (t \leq 1), \\
a_{t}=a-b & (t \geq 2) .
\end{array}
$$

The value of parameter $b$ is announced in period 1 , one period before the productivity fall takes place. It could be equal to zero, in which case productivity remains unchanged. As we shall see, the economy falls in a liquidity trap when the value of $b$ is large enough. The realization of $b$ is governed by a probability distribution function that is known by all agents, and expectations are rational.

It then follows from (2.15) and (2.18) that the log of potential output and the log of the natural real exchange rate also fall by $b$ in period 2

$$
\begin{array}{ll}
\bar{y}_{t}=\bar{y} \text { and } \bar{q}_{t}=\bar{q} & (t \leq 1), \\
\bar{y}_{t}=\bar{y}-b \text { and } \bar{q}_{t}=\bar{q}-b & (t \geq 2),
\end{array}
$$

with $\bar{y}$ and $\bar{q}$ defined by

$$
\begin{aligned}
\bar{y} & \equiv \ln \left(\frac{\xi-1}{\xi}(1-\alpha)\right)+a, \\
\bar{q} & \equiv \ln \frac{\alpha}{1-\alpha}+\bar{y}-\bar{c}_{f} .
\end{aligned}
$$

Taking the log of (2.22) — and using that potential output is known one period in advance - we get

$$
\bar{r}_{t}=r^{*}+(1-\alpha)\left(\bar{y}_{t+1}-\bar{y}_{t}\right)=r^{*}+(1-\alpha)\left(a_{t+1}-a_{t}\right) .
$$

Thus, the natural interest rate is directly related to the rate of time preference, $-\ln \delta=r^{*}$, and to expected productivity growth, $a_{t+1}-a_{t}$. Expected productivity growth is constant and equal to zero in all periods, except in period 1 when it is falls to $-b$. Consequently, the natural interest rate is equal to $r^{*}$ in all periods, except in period 1 when it falls to

$$
\bar{r}_{1}=r^{*}-(1-\alpha) b \text {. }
$$

Furthermore, the logs of money, prices, and output will be related by

$$
\begin{array}{ll}
m_{t}-p_{h t}=g\left(y_{t}, i_{t}\right) & \left(i_{t}>0\right), \\
m_{t}-p_{h t} \geq \mu & \left(i_{t}=0\right),
\end{array}
$$


where $g\left(y_{t}, i_{t}\right) \equiv \ln G\left(e^{y_{t}}, i_{t}\right)$.

As shown in appendix $\mathrm{C}$, the model can be solved under rational expectations for an arbitrary distribution of $b$. For expositional simplicity, however, we assume in the main text that economic agents view the lower expected productivity growth in period 1 as very unlikely ex ante. Hence, until period 0 they behave as if $b$ were going to be equal to zero, and the lower expected productivity growth comes to them as an unexpected surprise in period 1. Examining this simple case makes the algebra easier and, as shown in the appendix, it does not affect the essence of our results on the optimal policy to escape a liquidity trap.

\subsection{Monetary policy}

Assume that the central bank has an objective function corresponding to "flexible (CPI) inflation targeting," with an intertemporal loss function

$$
\mathrm{E}_{t} \sum_{\tau=0}^{\infty}(1-\delta) \delta^{\tau} L_{t+\tau}
$$

with the period loss function

$$
L_{t}=\frac{1}{2}\left[\left(\pi_{t}-\pi\right)^{2}+\lambda\left(y_{t}-\bar{y}_{t}\right)^{2}\right]
$$

where $\pi_{t}=\log \left(P_{t} / P_{t-1}\right)$ is the inflation rate, $\pi \geq 0$ is a given inflation target, $y_{t}-\bar{y}_{t}$ is the output gap, and $\lambda>0$ is a given weight on output-gap stabilization. We assume that the central bank cannot commit to future policy actions and, hence, that it in each period $t$ minimizes the period loss function (2.30) under discretion, for given private-sector expectations of future inflation. ${ }^{5}$

Let us derive the equilibrium inflation rate. Taking the log of (2.1) and (2.17), inflation can be written

$$
\pi_{t} \equiv p_{t}-p_{t-1}=p_{h t}+\alpha q_{t}-p_{t-1}
$$

Taking the log difference of (2.18) and (2.19), we find that the log deviations of output and of the real exchange rate from their natural levels are equal,

$$
q_{t}-\bar{q}_{t}=y_{t}-\bar{y}_{t}
$$

Using this equation to substitute for $q_{t}$ in (2.31) gives the following Phillips curve,

$$
\pi_{t}=\left(\alpha \bar{q}_{t}+p_{h t}-p_{t-1}\right)+\alpha\left(y_{t}-\bar{y}_{t}\right) .
$$

\footnotetext{
${ }^{5}$ Since the central bank's target level for output equals potential output, there will not be any average inflation bias in a discretion equilibrium.
} 
The first term on the right side involves variables that are either exogenous $\left(\bar{q}_{t}\right)$ or predetermined ( $p_{h t}$ and $\left.p_{t-1}\right)$. The second term implies that the slope of the short-run Phillips curve is $\alpha$.

The central bank will be able to control $i_{t}$ by setting $m_{t}$. For given inflation expectations, this will determine $r_{t}$ and $y_{t}$. Via $(2.33), \pi_{t}$ is then determined. For simplicity, we can think of the central bank as choosing $y_{t}$ directly, and then inferring the corresponding level of $m_{t}$ from (2.28).

We will see below that a liquidity trap can only arise in period 1, when expected productivity growth and the natural interest rate are low. In all other periods, there is no liquidity trap. Then (2.33) is the only relevant constraint. In those periods, the central bank's optimization problem under discretion is to minimize the period loss function (2.30) subject to the Phillips curve (2.33). This implies the targeting rule (first-order condition)

$$
\pi_{t}-\pi=-\frac{\lambda}{\alpha}\left(y_{t}-\bar{y}_{t}\right)
$$

The only period in which new information is revealed is period 1 . In all other periods $t \neq 1$, there is no new information, and $y_{t}$ is known in the previous period, $t-1$. Equation (2.16) then implies that output equals potential output, $y_{t}=\bar{y}_{t}$, equation (2.32) implies that the real exchange rate equals the natural real exchange rate rate, $q_{t}=\bar{q}_{t}$, and the first-order condition (2.34) implies that the inflation rate equals the inflation target. The real exchange rate is constant for $t \geq 2$, implying that the price of the home good and the nominal exchange rate increase at the same rate $\pi$. The same argument applies for $t \leq 0$, and we have the following result ( $s_{t}$ denotes the log exchange rate):

Proposition 2.1. Under discretion, for $t \leq 0$ and $t \geq 2, y_{t}=\bar{y}_{t}, q_{t}=\bar{q}_{t}$, and $p_{h t}-p_{h, t-1}=\pi_{t}=$ $s_{t}-s_{t-1}=\pi$.

\subsection{A liquidity trap in period 1}

Having characterized the equilibrium in periods other than 1, we now focus on period 1 . We can summarize the model in period 1 as

$$
\begin{gathered}
y_{1}-\bar{y}=-\frac{1}{1-\alpha}\left(r_{1}-\bar{r}_{1}\right) \leq \frac{1}{1-\alpha}\left(\bar{r}_{1}+\pi_{2}\right), \\
\pi_{1}-\pi=\alpha\left(y_{1}-\bar{y}\right) .
\end{gathered}
$$

Equation (2.35) is obtained by taking the $\log$ of (2.21) and (2.22) for $t=1$ and observing that perfect foresight applies from period 1 onwards. The inequality follows from the zero lower bound 
on the home nominal interest rate and the relation between the nominal and real interest rate in period 1 ,

$$
i_{1}=r_{1}+\pi_{2} \geq 0
$$

Equation (2.36) follows from (2.33), $\bar{y}_{1}=\bar{y}, \alpha \bar{q}_{1}+p_{h 1}-p_{0}=\alpha\left(\bar{q}_{1}-q_{0}\right)+\Delta p_{h 1}, q_{0}=\bar{q}_{1}=\bar{q}$, and the fact that $\Delta p_{h 1} \equiv p_{h 1}-p_{h 0}$ was set equal to $\pi$ in period 0 (because the drop in productivity was unanticipated).

The economy is in a liquidity trap in period 1, if the constraint (2.37) prevents the central bank from setting output at its potential level, that is, if $\bar{r}_{1}+\pi_{2}<0$. By Proposition 2.1, in a discretion equilibrium, the inflation rate will be set to $\pi_{2}=\pi$ in period 2. By (2.27), we then have the following result.

Proposition 2.2. The economy falls in a liquidity trap in period 1 if and only if the natural interest rate is sufficiently negative,

$$
\bar{r}_{1}<-\pi \leq 0
$$

that is, if and only if the fall in expected productivity growth is sufficiently large,

$$
b>\frac{r^{*}+\pi}{1-\alpha}>0
$$

In a discretion equilibrium with a liquidity trap in period 1, the best the central bank can do is to set $m_{1} \geq p_{h 1}+\mu$, so the nominal interest rate will equal zero, $i_{1}=0$. We let ${ }^{\wedge}$ denote the values of variables in the discretion equilibrium, so $\hat{y}_{1}, \hat{\pi}_{1}$, and $\hat{r}_{1}$ denote the corresponding values of output, inflation, and the real interest rate. From the binding constraints (2.35) and (2.37), it follows that

$$
\begin{aligned}
\hat{y}_{1}-\bar{y} & =\frac{1}{1-\alpha}\left(\bar{r}_{1}+\pi\right)<0, \\
\hat{\pi}_{1}-\pi & =\frac{\alpha}{1-\alpha}\left(\bar{r}_{1}+\pi\right)<0, \\
\hat{r}_{1}-\bar{r}_{1} & =-\left(\bar{r}_{1}+\pi\right)>0 .
\end{aligned}
$$

The output gap and the inflation gap are negative, and the real interest-rate gap is positive.

\subsection{The optimal policy under commitment}

The above equilibrium is suboptimal, with a negative output gap that is unnecessary large, because private-sector inflation expectations are equal to the inflation target. If possible, it would be better 
for the central bank to credibly commit to exceeding the inflation target next period, period 2, and this way create private-sector expectations in period 1 of a higher period-2 inflation. This would lower the real interest rate and reduce the magnitude of the output gap in period 1 . In order to specify this optimal policy - the optimal escape from a liquidity trap — we consider the optimal policy in a liquidity trap under commitment.

The relevant loss function in period 1 is then

$$
L_{1}+\frac{1}{2} \delta\left(\pi_{2}-\pi\right)^{2}=\frac{1}{2}\left[\left(\pi_{1}-\pi\right)^{2}+\lambda\left(y_{1}-\bar{y}\right)^{2}+\delta\left(\pi_{2}-\pi\right)^{2}\right] .
$$

In period 2, we have $y_{2}=\bar{y}_{2}=\bar{y}-b$, so there cannot be any surprise and liquidity trap in period 2. Hence, the period-2 output-gap term vanishes from (2.40). In addition, since there will not be any surprise in period 2 , there will not be any uncertainty about period- 2 inflation, $\pi_{2}$, so actual rather than expected inflation appears in (2.40).

The central bank minimizes (2.40) subject to (2.35) and (2.36). We now consider $\pi_{2}$ as a control variable, in addition to $y_{1}$. The Lagrangian is

$$
\mathcal{L}_{1}=\frac{1}{2}\left[\left(\pi_{1}-\pi\right)^{2}+\lambda\left(y_{1}-\bar{y}\right)^{2}+\delta\left(\pi_{2}-\pi\right)^{2}\right]-\varphi_{1}\left[\frac{1}{1-\alpha}\left(\bar{r}_{1}+\pi_{2}\right)-y_{1}+\bar{y}\right],
$$

where $\varphi_{1} \geq 0$ is the Lagrange multiplier for the constraint (2.35) and we will use (2.36) to substitute for $\pi_{1}-\pi$. The first-order conditions with respect to $y_{1}$ and $\pi_{2}$ and the complementary-slackness condition are then, respectively,

$$
\begin{aligned}
\alpha\left(\pi_{1}-\pi\right)+\lambda\left(y_{1}-\bar{y}\right)+\varphi_{1} & =0, \\
\delta\left(\pi_{2}-\pi\right)-\frac{1}{1-\alpha} \varphi_{1} & =0 \\
\varphi_{1}\left[\frac{1}{1-\alpha}\left(\bar{r}_{1}+\pi_{2}\right)-y_{1}+\bar{y}\right] & =0 .
\end{aligned}
$$

In a liquidity trap, $\varphi_{1}>0$. Eliminating $\varphi_{1}$ from (2.41)-(2.43) results in the targeting rule under commitment in a liquidity trap: ${ }^{6}$ Set $m_{1} \geq p_{h 1}+\mu$ and thereby $i_{1}=0$, and choose $\pi_{2}>\pi$, and thereby

$$
y_{1}-\bar{y}=\frac{1}{1-\alpha}\left(\bar{r}_{1}+\pi_{2}\right)
$$

so as to fulfill the target criterion

$$
\pi_{2}-\pi=-\frac{\alpha}{\delta(1-\alpha)}\left(\pi_{1}-\pi\right)-\frac{\lambda}{\delta(1-\alpha)}\left(y_{1}-\bar{y}\right)>0
$$

${ }^{6}$ Outside a liquidity trap, under commitment, the central bank would just set $m_{1}$ and $i_{1}$ such that $y_{1}=\bar{y}$ and set $\pi_{2}=\pi$. 
The commitment equilibrium in the liquidity trap is then determined by (2.36), (2.44), and (2.45). We let $\sim$ denote the values of variables in the commitment equilibrium. Combining (2.36), (2.44), and (2.45), we get

$$
\begin{gathered}
\tilde{y}_{1}-\bar{y}=\frac{\delta(1-\alpha)}{\delta(1-\alpha)^{2}+\alpha^{2}+\lambda}\left(\bar{r}_{1}+\pi\right)<0, \\
\tilde{\pi}_{2}-\pi=-\frac{\alpha^{2}+\lambda}{\delta(1-\alpha)^{2}+\alpha^{2}+\lambda}\left(\bar{r}_{1}+\pi\right)>0, \\
\tilde{r}_{1}-\bar{r}_{1}=-\frac{\delta(1-\alpha)^{2}}{\delta(1-\alpha)^{2}+\alpha^{2}+\lambda}\left(\bar{r}_{1}+\pi\right)>0,
\end{gathered}
$$

where the last equation follows from (2.35) and (2.46).

Comparing the output gap in the commitment equilibrium, (2.46), with that in the discretion equilibrium, (2.38), we see that

$$
\tilde{y}_{1}-\bar{y}>\hat{y}_{1}-\bar{y}
$$

The magnitude of the negative output gap is less than under discretion. By (2.36), it follows that the magnitude of the negative inflation gap in period $1, \tilde{\pi}_{1}-\pi$, is also smaller, $\tilde{\pi}_{1}-\pi>\hat{\pi}_{1}-\pi$. The optimal policy trades off the right amount of period- 2 overshoot of the inflation target, $\tilde{\pi}_{2}-\pi>0$, for the right amount of increase in the period-1 output and partial closing of the output gap. The higher period-2 inflation results in a smaller real-interest-rate gap, $\tilde{r}_{1}-\bar{r}_{1}<\hat{r}_{1}-\bar{r}_{1}$.

\subsection{Implementing the commitment equilibrium}

The commitment equilibrium will imply a period-2 money supply, $\tilde{m}_{2}$, given by

$$
\tilde{m}_{2}=\tilde{p}_{2 h}+g\left(\bar{y}-b, r^{*}+\pi\right)=\tilde{p}_{2}-\alpha(\bar{q}-b)+g\left(\bar{y}-b, r^{*}+\pi\right)
$$

where $\tilde{p}_{2 h}$ and $\tilde{p}_{2} \equiv p_{0}+\tilde{\pi}_{1}+\tilde{\pi}_{2}$ are the period-2 home-good and CPI price levels, respectively, and we use that $\tilde{p}_{2 h}=\tilde{p}_{2}-\alpha \bar{q}_{2}, \bar{q}_{2}=\bar{q}-b, y_{2}=\bar{y}_{2}=\bar{y}-b$, and $i_{2}=r^{*}+\pi$.

The commitment equilibrium can be implemented, if the central bank can commit in period 1 to a period-2 money supply equal to $\tilde{m}_{2}$. Indeed, this would be the most direct way to implement the optimal escape from a liquidity trap, and as noted by Krugman [12] and more recently by Auerbach and Obstfeld [2], an expansion of the money supply that is perceived to be permanent will be effective. However, as emphasized in Krugman [12] and Svensson [20], in the real world, there is no direct mechanism through which central banks can commit to a particular future money supply. 
Indeed, since the spring of 2001, the Bank of Japan has expanded the monetary base by more than 60 percent. If this expansion had been perceived as permanent, it would have resulted in dramatically increased expectations of future inflation in Japan, which would have shown up in either a large depreciation of the yen or a large rise in long interest rates. Obviously, none of this has happened, and the obvious explanation is that the Bank of Japan is expected to contract the monetary base in the future.

We will show below that we can find a different commitment mechanism through which the central bank can commit to a higher future price level, namely through a credible commitment to a weaker currency. For this purpose, we will specify the exchange rates consistent with the commitment and discretion equilibria. Using (2.17) and (2.32), the period-1 log exchange rate in the commitment equilibrium is

$$
\tilde{s}_{1}=p_{h 1}+\tilde{q}_{1}=p_{h 1}+\bar{q}+\tilde{y}_{1}-\bar{y}
$$

with $\tilde{y}_{1}-\bar{y}$ given by (2.46). The period-2 exchange rate can be derived from uncovered interest parity, which follows from the log of (A.1) in appendix A and the fact that, under our assumptions, there will be no surprise in period 2 ,

$$
i_{1}=r^{*}+s_{2}-s_{1}
$$

which, since the nominal interest rate is equal to zero in the liquidity trap, implies

$$
\tilde{s}_{2}=\tilde{s}_{1}-r^{*}
$$

The central bank can implement the commitment equilibrium, if it can credibly commit itself to pegging the exchange rate at the optimal levels $\tilde{s}_{1}$ and $\tilde{s}_{2}$ given by (2.49) and (2.51). That is, the central bank would make a credible commitment to buy and sell unlimited amounts of foreign exchange at those exchange rates. In a commitment equilibrium, it would then not have to make any unlimited foreign-exchange interventions, but just the foreign-exchange interventions that result in money supplies $m_{1} \geq p_{h 1}+\mu$ and $m_{2}=\tilde{m}_{2}$. The problem with such a commitment is, however, that it will not be credible, if the central bank reoptimizes under discretion in period 2.

In order to see this, suppose that the central bank has credibly implemented the optimal policy in period 1 , resulting in the output gap $\tilde{y}_{1}-\bar{y}$ and the inflation gap $\tilde{\pi}_{1}-\pi$ in period 1 , as well as expectations in period 1 of inflation in period 2 equal to $\tilde{\pi}_{2}$. These expectations would then result in period-1 pricing decisions resulting in the corresponding home-good price level $\tilde{p}_{h 2}$. By (2.33), 
this implies that, in period 2, the central bank faces the Phillips curve

$$
\pi_{2}-\tilde{\pi}_{2}=\alpha\left(y_{2}-\bar{y}_{2}\right)
$$

where ex post inflation $\pi_{2}$ and output $y_{2}$ could differ from the levels expected in period 1, $\tilde{\pi}_{2}$ and $\bar{y}_{2}$. If the central bank reoptimizes under discretion in period 2 , that is, minimizes the period loss function (2.30) for $t=2$, the corresponding first-order condition is

$$
\pi_{2}-\pi=-\frac{\lambda}{\alpha}\left(y_{2}-\bar{y}_{2}\right) .
$$

Combining (2.52) and (2.53) results in

$$
\pi_{2}=\frac{\alpha^{2}}{\alpha^{2}+\lambda} \pi+\frac{\lambda}{\alpha^{2}+\lambda} \tilde{\pi}_{2}<\tilde{\pi}_{2} .
$$

That is, ex post, the central bank would renege on its commitment to implement the optimal inflation rate $\tilde{\pi}_{2}$ in period 2 and instead implement a lower inflation rate. Anticipation of this reneging by the private sector in period 1 would unravel the commitment equilibrium.

The above reneging cannot arise in the formulation of the Foolproof Way in Svensson [21]. There, monetary policy is concerned about domestic inflation, inflation in the home-currency price of home goods, with the period loss function (in the notation of the present paper)

$$
L_{t}=\frac{1}{2}\left[\left(p_{h t}-p_{h, t-1}\right)^{2}+\lambda\left(y_{t}-\bar{y}_{t}\right)^{2}\right]
$$

where domestic inflation, $p_{h t}-p_{h, t-1}$, enters rather than CPI inflation, $p_{t}-p_{t-1}$. Since the period- $t$ domestic price level and domestic inflation is predetermined by pricing decisions in period $t-1$, the central bank cannot renege. Indeed, the discussion of the price level in the context of the Foolproof Way in Svensson [19]-[21] has consistently referred to the domestic price level rather than the CPI price level. In the present set up, with monetary policy concerned about CPI inflation and instantaneous pass-through of exchange-rate movements to home-currency prices of the foreign good, the period- $t$ CPI price level and CPI inflation are directly affected by the period- $t$ exchange rate, $p_{t}=(1-\alpha) p_{h t}+\alpha s_{t}$, and reneging is possible.

Conditional on the assumption of reoptimization under discretion in period 2 , the only equilibrium in the present setup in period 1 is the discretion equilibrium, the equilibrium we have characterized in section 2.5. The corresponding log exchange rates in the discretion equilibrium are given by

$$
\begin{aligned}
& \hat{s}_{1}=p_{h 1}+\hat{q}_{1}=p_{h 1}+\bar{q}+\hat{y}_{1}-\bar{y}<\tilde{s}_{1}, \\
& \hat{s}_{2}=\hat{s}_{1}-r^{*}<\tilde{s}_{2} .
\end{aligned}
$$


The exchange rates in the two periods are lower by the same amount - the currency is strongerin the discretion equilibrium than in the commitment equilibrium.

In the rest of the paper, we argue that a commitment mechanism for a commitment to the optimal exchange rates, $\left(\tilde{s}_{1}, \tilde{s}_{2}\right)$, can be found, provided that we add a simple and plausible assumption to the model. This assumption is related to concerns that real-world central banks have with their level of capital. The next section presents some evidence on these concerns.

\section{The balance-sheet concerns of central banks}

In the following sections, we extend our model by assuming that the central bank does not let its capital fall below some threshold, and that this concern may override the macroeconomic objectives for output and inflation. This section presents some evidence supporting the realism of this assumption.

At the outset, it should be noted that the central bank's concern for its level of capital is not obvious. Central banks do not need a positive level of capital for the same reasons as commercial banks. A negative level of capital does not subject them to the risk of a run and a bankruptcy, since they can always face their debt obligations by printing currency. So, strictly speaking, central banks do not need capital (Stella [17]). If the central bank were consolidated with the central government, there would be no reason to consider the central bank's capital separately from the intertemporal budget constraint of the government.

However, central banks have balance sheets that are constructed according to the same broad principles as private banks. ${ }^{7}$ Central banks, furthermore, seem to be concerned by their capital as their private counterparts. This is illustrated by several facts.

First, central-bank capital, although it can be quite low, is generally positive. In 2003, the median level of central-bank capital (including reserves and provisions) represented 8.8 percent of its total assets in emerging economies and 15.3 percent in advanced countries (Hawkins [10]). In some countries, the central banks have had negative capital for prolonged periods of time, but these are mostly Latin American countries with a history of monetary instability (Stella [18]).

Second, the level of capital seems closely related to the proportion of central-bank assets held

\footnotetext{
${ }^{7}$ Each year, the central bank's capital is increased or decreased by the amount of retained earnings or losses. Retained earnings are equal to the profit minus the dividend paid to the government and/or other shareholders. Although the accounting rules differ across central banks, the profit may include valuation changes on most assets, in particular, foreign-exchange reserves. When it does not, these valuation changes are included in a separate valuation account on the liability side of the balance sheet, which can be viewed as a component of the bank's capital broadly defined.
} 
Figure 3.1: Central Banks' Capital and Reserves 1999-2003

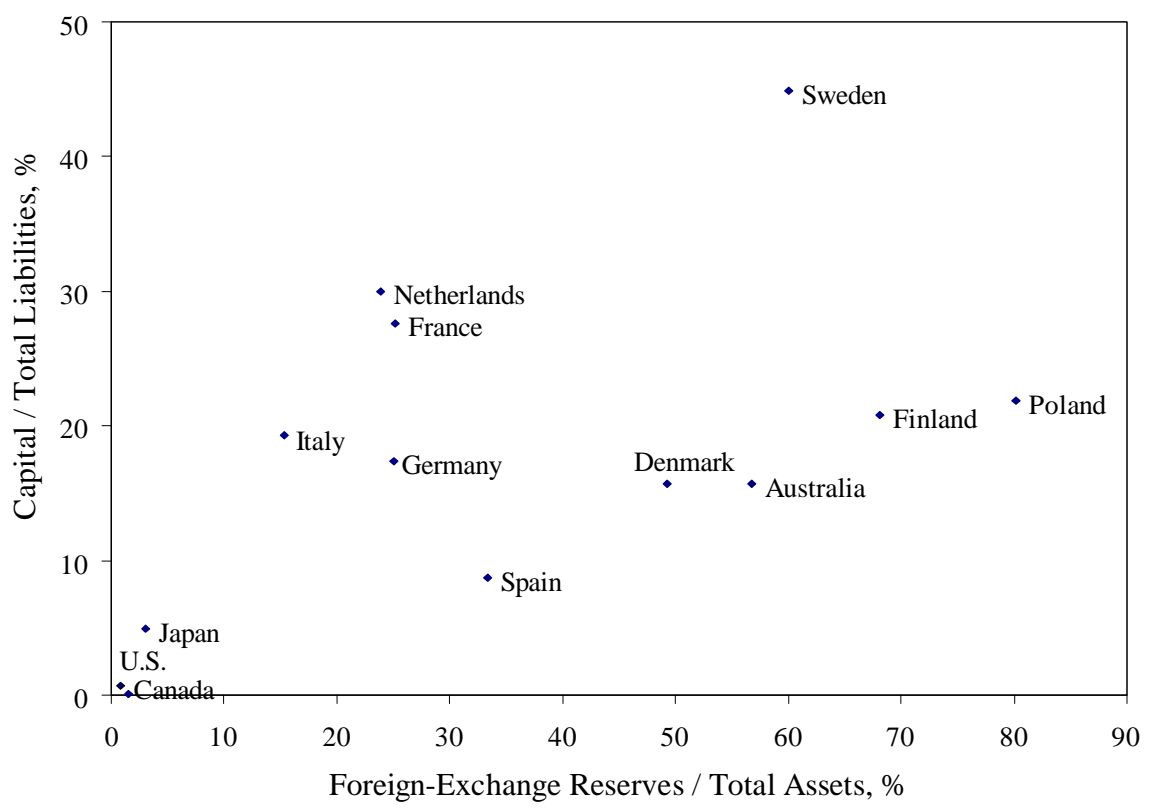

as foreign-exchange reserves and thereby the amount of foreign-exchange risk they bear. ${ }^{8}$ Figure 3.1 plots the ratio of central-bank capital to total liabilities against the ratio of foreign-exchange reserves to total assets, for a sample of OECD countries. ${ }^{9}$ The figure illustrates the distinction made by Sims [16] between two types of central banks. Some central banks (Sims's type F) have a low proportion of their assets as foreign-exchange reserves and have low capital ratios. One example is the U.S. Federal Reserve System: it holds very little foreign-exchange reserves, and so does not need a large amount of capital to buffer the exchange risk. This category also includes countries that have large total foreign-exchange reserves but in which most of these reserves are held by the Treasury (Canada and Japan). The other type of central banks (Sims's type E) have a higher proportion of assets as foreign-exchange reserves, and accordingly maintain a higher capital ratio. This category includes most European central banks. ${ }^{10}$

\footnotetext{
8 The other risky asset held by central banks is gold. However, gold is generally not risky from an accounting point of view because of accounting rules that insulate the balance sheet from variations in its market price. Many countries ignore changes in the market price of gold by utilizing a historical price set in foreign currency (frequently the U.S. dollar or SDR). By contrast, foreign exchange reserves are generally valued at the market exchange rates.

${ }^{9}$ The figure reports averages over 1999-2002, based on the annual reports of the central banks. Our measure of capital includes reserves and revaluation accounts. Details are available from the authors upon request.

10 Central banks in the Eurosystem have a valuation account on the liabilities side of their balance sheets as a reserve against valuation losses arising from changes in the exchange rate. This account reflects net gains from valuation changes that are not distributed but set aside as reserve against future losses from exchange rate changes. When a valuation loss due to a change in the exchange rate occurs, the amount of the loss is deducted from the balance of the valuation account. In case the balance of this account is insufficient to cover the loss, it is included in the profit-and-loss account.
} 
Third, an increasing number of central banks explicitly define an objective in terms of a capitaladequacy ratio. Since 1998, the Bank of Japan targets a capital-adequacy ratio, consisting of the capital divided by a period average of outstanding bank notes, of around 8-12 percent (Cargill [4], Stella [18]). Recent legislation in Indonesia prevents the transfer of profits to the government until the central bank builds its capital up to 10 percent of its monetary liabilities. The Reserve Bank of India aims at capital and reserves of 8 percent of assets (Hawkins [10]).

The central banks' revealed preferences suggest a strong aversion to negative or low capital. But why is it so? The reasons given by central banks suggest that this has to do mainly with the autonomy of their institutions relative to the government. As the governor of the Bank of Japan put it in a recent speech (Fukui [8]),

$[\mathrm{C}]$ entral banks' concern with the soundness of their capital base might not be grounded purely in economic theory but may be motivated rather by the political economy instincts of central bankers. In other words, once the restriction that "the central bank should only take risks consistent with the level of its self-imposed capital base" is violated, the boundary between the functions of the central bank and those of the government may become difficult to discern.

The relationship between central-bank independence and central-bank losses goes both ways. First, a central bank that is not independent is more likely to make losses. These losses are typically the result of accounting rules or of the transfer to the central bank of quasi-fiscal activities (subsidized lending, bank bailouts) that make it possible for the government to artificially reduce the headline fiscal deficit (Leone [13]).

Conversely, an independent central bank that makes large losses will see its independence eroded over time. A loss-making central bank is likely to become the object of increased oversight from the government - as any loss-making public entity should be. But the government might take advantage of increased oversight to influence monetary policy (Vaez-Zadeh [15]; Ernhagen, Vesterlund and Viotti [7]). As noted by Pringle [14, pp. 78 and 80]:

What would happen if the BoJ had to report huge paper losses? Public reaction would be all important.... Also, the government might say that it would inject capital on certain conditions - e.g., that the central bank changed its monetary policy.

\section{How an independent central bank can commit to a future price level}

Consider a central bank that finds itself in a liquidity trap in period 1 . The central bank cannot commit to a particular money supply in the future. We will show that it can, nevertheless, move 
to and implement the commitment equilibrium in period 1 by managing its balance sheet in the right way. Thereby it can commit itself to an exchange-rate in period 2 that corresponds to the desired higher next-period inflation, $\tilde{\pi}_{2}$.

Define the central bank's capital at the end of period $t, V_{t}$, as

$$
V_{t} \equiv S_{t} R_{t}-M_{t}
$$

We note that, by (2.6) and (4.1),

$$
V_{t}=S_{t} e^{r^{*}} R_{t-1}-M_{t-1}-Z_{t}
$$

so the only non-predetermined variables in period $t$ that the capital $V_{t}$ depends on are the exchange rate, $S_{t}$, and the dividend paid to the government during period $t, Z_{t}$.

Importantly, let us assume that the central bank never allows its capital to fall below a given nonnegative lower bound, $\bar{V}$,

$$
V_{t} \geq \bar{V} \geq 0
$$

The rationale for this, as explained in section 3 , is that too low a capital indicates mismanagement, causes embarrassment, might require the resignation of the bank management, and, more importantly, may force the central bank to ask for an injection of capital from the government, a negative dividend, for which it may have to give up some of its independence. In line with this, we also assume that the central bank has control over the dividend it pays and that this dividend is always nonnegative,

$$
Z_{t} \geq 0
$$

Thus, we find (4.3) and (4.4) to be realistic assumptions. Assume, furthermore, that the private sector believes that (4.3) and (4.4) always hold, that is, that the central bank will never voluntarily allow its capital to fall below the minimum level or the dividend to be negative.

The central bank enters period 1 with given $M_{0}$ and $R_{0}$. Suppose that the economy initially is in the discretion equilibrium in period 1 , with the period-1 exchange rate equal to $\hat{S}_{1}$, the expected period-2 exchange rate equal to $\hat{S}_{2}$, and with money supply, dividend, reserves and capital, denoted $\hat{M}_{1}, \hat{Z}_{1}, \hat{R}_{1}$, and $\hat{V}_{1}$, respectively, fulfilling

$$
\begin{gathered}
\hat{M}_{1}=\hat{Z}_{1}+\hat{S}_{1} \hat{R}_{1}+M_{0}-\hat{S}_{1} e^{r^{*}} R_{0} \geq P_{h 1} e^{\mu} \\
\hat{V}_{1}=\hat{S}_{1} e^{r^{*}} R_{0}-M_{0}-\hat{Z}_{1} \geq \bar{V} \geq 0
\end{gathered}
$$


where we have used (2.6) and (4.2) and we recall that $e^{\mu}>0$ is the satiation level of real money.

We want to show that the central bank can implement the commitment equilibrium by depreciating the currency in period 1 to the exchange rate $\tilde{S}_{1}>\hat{S}_{1}$ and committing to maintaining the exchange rate $\tilde{S}_{2}>\hat{S}_{2}$ in period $t+1$. This will then implement the optimal inflation, $\tilde{\pi}_{2}>\pi$, in period 2 and the optimal overshooting of the inflation target. The problem with this commitment, as explained in section 2.7, is that the private sector knows that the central bank has an incentive in period 2 to renege on its commitment and appreciate the currency below the exchange rate $\tilde{S}_{2}$, so as to achieve an ex post inflation rate closer to the inflation target. How can the central bank commit to not appreciating the currency in period 2? Our main result follows:

Proposition 4.1. The central bank can implement the commitment solution, $\tilde{S}_{1}$ and $\tilde{S}_{2}$, by pegging its exchange rate to $\tilde{S}_{1}$ and by setting its capital equal to the minimum level in period 1 ,

$$
V_{1}=\bar{V}
$$

To see why this is true, we note that, in period 2 , for given $R_{1}$ and $M_{1},(4.2),(4.3)$, and (4.4) imply a lower bound for the period-2 exchange rate,

$$
S_{2} \geq \frac{M_{1}+\bar{V}}{e^{r^{*}} R_{1}}
$$

This inequality comes from the currency mismatch in the balance sheet of the central bank. The central bank finances foreign-currency assets by issuing home-currency liabilities. The central bank's capital remains above the threshold $\bar{V}$ only if the value of the its foreign-exchange reserves is high enough in terms of home currency, that is, if the home currency is sufficiently depreciated. ${ }^{11}$

We then realize that the central bank should set and announce new levels of the money supply and the foreign-exchange reserves in period 1 , denoted $\tilde{M}_{1}$ and $\tilde{R}_{1}$, so that the central-bank capital in period 2, evaluated at the desired exchange rate, $\tilde{S}_{2}$, for a zero dividend payment in period 2 , $\tilde{Z}_{2}=0$, is exactly equal to the minimum level. Denote this level of the central bank's capital by $\tilde{V}_{2}$. Then we have

$$
\tilde{V}_{2} \equiv \tilde{S}_{2} e^{r^{*}} \tilde{R}_{1}-\tilde{M}_{1}=\bar{V}
$$

This implies that the lower bound for the period-2 exchange rate, the right side of (4.7) for period 2 , is exactly equal to $\tilde{S}_{2}$. Furthermore, the central bank will never choose a higher exchange rate

\footnotetext{
11 Note the contrast with the currency mismatches that are the focus of the recent literature on international financial crises (Aghion, Bacchetta and Banerjee [1]). There, domestic firms are indebted in foreign currency so that a depreciation reduces their net value.
} 
(weaker currency) in period 2 than this lower bound, because doing so would result in a CPI inflation rate even further away from the target and an even larger period-2 loss $L_{2}$. Therefore, it will then implement exactly the desired exchange rate $\tilde{S}_{2}$.

Using equations (4.1), (4.2), and the interest parity condition, $e^{i_{1}}=e^{r^{*}} S_{2} / S_{1}$, the central bank's capital in period 1 and period 2 are related as

$$
V_{2}=V_{1}+\left(e^{i_{1}}-1\right) S_{1} R_{1}-Z_{2}
$$

The central bank's capital increases by the revenues from seigniorage minus the dividend paid to the government. If the economy is in a liquidity trap $\left(i_{1}=0\right)$, the revenues from seigniorage are equal to zero. If the capital constraint is binding, furthermore, the central bank pays no dividend in period 2 , and we have

$$
V_{2}=V_{1}
$$

Hence, in order to set the value of its capital to the minimum level $\bar{V}$ in period 2, the central bank must set this value at the minimum level in period 1 . The end-of-period-1 capital evaluated at the exchange rate $\tilde{S}_{1}$, denoted $\tilde{V}_{1}$, fulfills

$$
\tilde{V}_{1} \equiv \tilde{S}_{1} e^{r^{*}} R_{0}-M_{0}-\tilde{Z}_{1}=\bar{V}
$$

Thus, in order to implement the commitment equilibrium, in period 1 the central bank should pay the dividend $\tilde{Z}_{1}$ to the government so as to make its capital in period 1 equal $\bar{V}$ when evaluated at the exchange rate $\tilde{S}_{1}$. Furthermore, it should adjust its money supply to exceed the satiation level, $\tilde{M}_{1}>P_{h 1} e^{\mu}$, and thereby ensure that the period-1 nominal interest rate is zero. Finally, it should make an explicit commitment to the peg of the exchange rate to $\tilde{S}_{1}$ and $\tilde{S}_{2}$, and, importantly, publish its balance sheet. This allows the private sector to verify that the central bank's capital in period 1 equals its minimum value at the exchange rate $\tilde{S}_{1}$, which implies that the central bank's capital will equal the minimum value also in period 2 at the exchange rate $\tilde{S}_{2}$. Then the commitment to the period-2 exchange rate will be credible, and $\tilde{S}_{1}$ will be the only exchange rate consistent with those period-2 expectations and uncovered interest parity. The commitment equilibrium is the only possible equilibrium.

It only remains to demonstrate that it is feasible for the central bank to choose a nonnegative dividend $\tilde{Z}_{1}$ that sets its capital equal to the minimum level in period 1 . This is the case, if its capital is larger than the minimum level conditional on a zero dividend, that is

$$
\tilde{S}_{1} e^{r^{*}} R_{0}-M_{0} \geq \bar{V}
$$


This is true by $(4.6)$ and $\tilde{S}_{1}>\hat{S}_{1}{ }^{12}$

If, counter to the above logic and announcements, the private sector, irrationally, would believe that the currency might appreciate back to $\hat{S}_{1}<\tilde{S}_{1}$ in period 1 , there will be excess demand for currency and excess supply of foreign-exchange reserves. The central bank can, however, always eliminate that excess demand and excess supply by issuing currency and buying foreign-exchange reserves, that is, by increasing $\tilde{R}_{1}$ and $\tilde{M}_{1}$, by the interventions $\Delta R_{1}$ and $\Delta M_{1}$ fulfilling $\Delta R_{1}=$ $\Delta M_{1} / \tilde{S}_{1}$. This maintains the central bank's capital at the level $\tilde{V}_{1}=\bar{V}$. Thus, we have shown not only that the central bank has the incentive to maintain the exchange rate at $\tilde{S}_{1}$ and $\tilde{S}_{2}$ in period 1 and 2 but that, in case there was nevertheless a speculative attack in the direction of appreciating the currency (lowering the exchange rate) from $\tilde{S}_{1}$ in period 1 , the central bank can actually defend currency peg at that rate. The reason is that a speculative attack in the direction of appreciating the currency can always be averted, since the resulting excess demand for home currency can always be fulfilled. ${ }^{13}$

\section{Generalizations}

We have shown how the central bank can commit to higher future inflation by pegging the exchange rate in a very simple model. The simplicity of the model is an advantage when explaining the logic of the argument, but raises the question of the robustness of our results to realistic changes in the assumptions.

\subsection{A multiperiod liquidity trap}

Would the balance-sheet channel still work if the liquidity trap lasted for several periods? A multiperiod liquidity trap could arise in the model if nominal prices were sticky for more than one period (Eggertsson and Woodford [6]). Let us simply assume, for the sake of this discussion, that the liquidity trap would end in period $\hat{T}>2$ under discretion, and that it is optimal to exit the liquidity trap in period $\tilde{T}$ under commitment, where $\tilde{T}$ may differ from $\hat{T}$. The commitment

\footnotetext{
12 The dividend payment, $\tilde{Z}_{1}$, will hence be positive. Since the government passes on the dividend to the private sector, the private sector receives a positive transfer. This transfer has, in itself, no effect on private-sector consumption and demand in this model, since Ricardian equivalence holds and the private sector fully internalizes the government and central-bank budget constraints (as in the derivation of consolidated home-country budget constraint, (2.9)).

13 This argument requires that the central bank stands ready to buy unlimited amounts of reserves. There is no cost for the bank of doing so, since money is neutral in the liquidity trap. If instead the central bank allowed the currency to appreciate when the level of reserves exceeds a certain level, there could be a speculative attack leading to an appreciation of the domestic currency (Grilli [9]).
} 
equilibrium will be associated with an exchange rate path $\tilde{S}_{1}, \tilde{S}_{2}, \ldots, \tilde{S}_{\tilde{T}}$, that satisfies

$$
\tilde{S}_{t+1}=e^{-r^{*}} \tilde{S}_{t} \text { for } t=1, \ldots, \tilde{T}-1
$$

The home currency must, by uncovered interest parity, appreciate at the foreign-currency interest rate, $r^{*}$, in each period, when the home-currency interest rate is zero.

As in the case of a one-period liquidity trap, the central bank can implement the commitment equilibrium, if it can commit itself to the exchange-rate path $\tilde{S}_{1}, \tilde{S}_{2}, \ldots, \tilde{S}_{\tilde{T}}$. It can do this, by making sure that its capital in period $\tilde{T}$, evaluated at the exchange rate $\tilde{S}_{\tilde{T}}$ and for a zero dividend in period $\tilde{T}, Z_{\tilde{T}}=0$, equals the minimum level,

$$
V_{\tilde{T}}=\bar{V}
$$

The central bank can achieve this by setting its capital, evaluated at the exchange rate $\tilde{S}_{1}$, equal to the minium level in period 1 ,

$$
V_{1}=\bar{V}
$$

Since the home nominal interest rate is zero in each period $t=1, \ldots, \tilde{T}-1$, this will, in equilibrium, make the central bank's capital equal to the minimum and the dividend equal to zero in each period $t=2, \ldots, \tilde{T}$. One can show this by demonstrating that it is optimal for the central bank to implement $S_{t}=\tilde{S}_{t}, Z_{t}=0$ and $V_{t}=\bar{V}$ in each period $t \leq \tilde{T}$, if it has done so until period $t-1$. This is a straightforward generalization of the proof for the two-period case. The constraints (4.2), (4.3), and (4.4) imply

$$
S_{t} \geq \frac{M_{t-1}+\bar{V}}{e^{r^{*}} R_{t-1}}
$$

By $V_{t-1}=\tilde{S}_{t-1} R_{t-1}-M_{t-1}=\bar{V}$ and $\tilde{S}_{t}=e^{-r^{*}} \tilde{S}_{t-1}$, this inequality implies

$$
S_{t} \geq \tilde{S}_{t}
$$

As in the one-period liquidity trap, this constraint will bind in equilibrium. The central bank will minimizes its period loss by setting $S_{t}=\tilde{S}_{t}, Z_{t}=0$ and $V_{t}=\bar{V}$.

\subsection{Generalizing the capital constraint}

Constraint (4.3), with a constant minimum capital level, is a simple but particular way of modeling the central bank's balance-sheet concerns. First, it would be natural to assume that the minimum level of capital $\bar{V}$ increases over time, at least in the long run. For example, if the objective of the 
central bank were to preserve the real value of its capital, the lower bound could be indexed on average inflation

$$
\bar{V}_{t}=\bar{V}_{0} e^{\pi t} \geq \bar{V}_{0}
$$

for $t \geq 0$ (since $\pi \geq 0)$.

Assume that the minimum capital is strictly increasing over time. For the one-period liquidity trap, it is easy to show that Proposition 4.1 still holds, except that the central bank now sets its period-1 capital to the period-2 minimum level,

$$
V_{1}=\bar{V}_{2}>\bar{V}_{1}
$$

so the capital will exceed the minimum level in period 1.

Similarly, for a multi-period liquidity trap with optimal exit in period $\tilde{T}>2$, the commitment to the exchange-rate level $\tilde{S}_{\tilde{T}}$ is achieved by setting the capital in period 1, evaluated at the exchange rate $\tilde{S}_{1}$, equal to the minimum level in period $\tilde{T}$,

$$
V_{1}=\bar{V}_{\tilde{T}}
$$

For zero dividend payments, this will keep the capital constant and equal to that minimum level for all periods $2, \ldots, \tilde{T}$, although the capital will exceed the minimum level in period $1, \ldots, \tilde{T}-1$,

$$
V_{t}=V_{1}>\bar{V}_{t} \quad(1 \leq t \leq \tilde{T}-1)
$$

The central bank might be tempted to increase its capital before period $\tilde{T}$, so as to renege on the commitment to $\tilde{S}_{T}$, but it cannot do so with a nonnegative dividend. Since its capital exceeds the minimum capital before period $\tilde{T}$, it could reduce its capital below $\bar{V}_{\tilde{T}}$, but this would force it to implement an even weaker currency in period $\tilde{T}$ (a higher exchange rate than $\tilde{S}_{\tilde{T}}$ ), which would increase its loss and not be optimal.

Second, some capital-adequacy rules may be problematic in a liquidity trap. For example, assume that the capital adequacy ratio is defined as a fraction of the supply of home currency,

$$
\bar{V}_{t}=\kappa M_{t}
$$

with $\kappa>0$ given (as in Japan). In a liquidity trap, the level of $M_{t}$ is undetermined, as long as it exceeds the satiation level of demand for home currency. Typically, the monetary base during the liquidity trap may be much higher than the equilibrium monetary base when the liquidity trap is over (cf. the above comments on the large expansion of the monetary base in Japan, which the 
private sector apparently expects to a large extent to be undone when Japan exits from the liquidity trap). But this means, under (5.1), that the minimum capital level will be much higher during the liquidity trap. This will prevent the central bank from reducing its capital to the minimum capital level in the period of exit from the liquidity trap. From the point of view of escaping a liquidity trap, it is preferable to define the minimum capital level as a given exogenous level rather than as a fraction of an endogenous monetary aggregate.

Finally, it might be realistic to assume more flexibility in the balance-sheet concerns of the central bank. The capital-adequacy objective could, for instance, be defined as an average over a number of periods. There could also be more symmetry between the balance-sheet objectives and the monetary-policy objectives of the central bank. For example, the central bank's balance-sheet concerns could be modeled as an additional term in its objective function instead of a constraint on its optimization problem. The period loss function (2.30) could be augmented with a term depending on the central bank's capital

$$
L_{t}=\frac{1}{2}\left[\left(\pi_{t}-\pi\right)^{2}+\lambda\left(y_{t}-\bar{y}_{t}\right)^{2}+\mu\left(v_{t}-\bar{v}\right)^{2}\right]
$$

where $\mu>0$ is the weight on the balance-sheet concerns, $v_{t}$ is the $\log$ of $V_{t}$ and $\bar{v}$ is the $\log$ of a target level of capital. The model would be the same as before as long as the central bank, without being restricted with regard to the monetary-policy objectives, can choose the level of dividends such that the level of capital is equal to the target level, $v_{t}=\bar{v}$. However, when the nonnegativity constraint on the dividend is binding, that is, when $v_{t}<\bar{v}$, there may be a tradeoff between the macroeconomic objectives and the balance-sheet concerns of the central bank. Other things equal, by increasing the dividend in a liquidity trap in period $t$ and reducing $v_{t+1}$ at an unchanged exchange rate in period $t+1$, the central bank can create incentives under discretion to depreciate its currency in period $t+1$. This way, the central bank can generate inflation expectations in period $t$ so as to reduce the real interest rate in period $t$ and improve the equilibrium under discretion. Central-bank capital hence still provides a predetermined state variable that the central bank can use to create a commitment mechanism.

\subsection{Pegging the price of other assets than foreign exchange}

As noted in section 3, in some countries (including Japan), the central bank holds only a small amount of foreign-exchange reserves. Most of the foreign-exchange reserves are held, and the associated risk is born, by the Treasury. This does not necessarily prevent these central banks to 
optimally escape a liquidity trap with an exchange rate peg since - as shown in appendix D - the results of section 4 remain true even if the central holds small foreign-exchange reserves, as long as they are positive. This is because when the capital constraint is binding, the minimum level that it implies for the exchange rate does not depend on the amount of foreign-exchange reserves. In principle, therefore, the commitment mechanism presented in this paper could work with a very small amount of foreign-exchange reserves.

The amount of foreign-exchange reserves is irrelevant because the balance-sheet concerns of the central banker are modeled as the constraint (4.3). If instead these concerns were modeled with the loss function (5.2), then the amount of foreign-exchange reserves would matter, since it would determine the sensitivity of the central bank's capital to the exchange rate. In this case, the central bank might have to increase its foreign-exchange reserves drastically in order to tie its hands using the foolproof way. Alternatively, the desired commitment might be achieved by pegging the price of assets other than foreign-exchange reserves. What other assets could be used for this purpose?

We show in this section that the balance-sheet management can be generalized to some, but not all assets. The important distinction in this regard is between the assets whose returns are predetermined in home currency ("nominal" assets, such as home-currency bonds of all maturities) and assets whose returns are not predetermined ("real" assets, such as stocks, real estate or indexed bonds). The latter, and the not the former, provide the appropriate tool for the sort of commitment strategies we have analyzed so far.

Consider the case of an inflation-indexed consol that yields a positive nominal coupon payment of $\rho P_{t}$ in each period $t$, where $\rho>0$ (the result can be generalized to other assets such as stocks, but it is easiest to show it with an indexed consol). Let $P_{t}^{c}$ denote the home-currency price of the consol in period $t$ (after the payment of the interest in period $t$ ). In equilibrium, investing in the consol and reselling it the following period will yield the same return as investing in a one-period home-currency bond

$$
\frac{\rho P_{t+1}+P_{t+1}^{c}}{P_{t}^{c}}=e^{i_{t}} .
$$

From the fact that, from period $t=2$ onwards, $P_{t}$ and $P_{t}^{c}$ increase at the rate $\pi$ and $i_{t}=r^{*}+\pi$, it follows that the nominal price of the consol is proportional to the CPI,

$$
P_{t}^{c}=\frac{\rho}{e^{r^{*}}-1} P_{t} \quad(t \geq 2)
$$

From (5.3), (5.4), and $e^{i_{1}}=1$, it follows that the price of the consol in period 1 is

$$
P_{1}^{c}=e^{r^{*}} P_{2}^{c}
$$


The commitment solution can then be implemented by pegging the price of the consol to the levels in period 1 and $2, \tilde{P}_{1}^{c}$ and $\tilde{P}_{2}^{c}$, that would arise in the commitment equilibrium. These levels are given by

$$
\begin{aligned}
\tilde{P}_{1}^{c} & \equiv \frac{\rho e^{r^{*}}}{e^{r *}-1} \tilde{P}_{2}, \\
\tilde{P}_{2}^{c} & \equiv \frac{\rho}{e^{r *}-1} \tilde{P}_{2},
\end{aligned}
$$

where $\tilde{P}_{2}$ is the period-2 CPI in the commitment equilibrium.

Assume that consols are the only assets on the central bank's balance sheet, and let $X_{t}$ denote the number of consols held by the central bank between period $t$ and period $t+1$. Then the central bank's budget constraint is

$$
Z_{t}+P_{t}^{c} X_{t}=M_{t}-M_{t-1}+\left(P_{t}^{c}+\rho P_{t}\right) X_{t-1}
$$

and its capital is given by

$$
\begin{aligned}
V_{t} & =P_{t}^{c} X_{t}-M_{t} \\
& =\left(P_{t}^{c}+\rho P_{t}\right) X_{t-1}-M_{t-1}-Z_{t}
\end{aligned}
$$

In particular, the period-2 level of capital is given by

$$
V_{2}=e^{r^{*}} P_{2}^{c} X_{1}-M_{1}-Z_{2}
$$

where we have used (5.4) for $t=2$ to replace $P_{2}^{c}+\rho P_{2}$. The capital constraint $V_{2} \geq \bar{V}$ and the dividend constraint $Z_{2} \geq 0$ then imply

$$
P_{2}^{c} \geq \frac{M_{1}+\bar{V}}{e^{r^{*}} X_{1}}
$$

in analogy with (4.7). This sets a lower bound on the price of consols in period 2-and, because of (5.4), also on the period-2 CPI. In period 1, the central bank should then choose $M_{1}$ and $X_{1}$ at levels $\tilde{M}_{1}$ and $\tilde{X}_{1}$ such that the lower bound equals the commitment level $\tilde{P}_{2}^{c}$, that is,

$$
\frac{\tilde{M}_{1}+\bar{V}}{e^{r^{*}} \tilde{X}_{1}}=\tilde{P}_{2}^{c}
$$

By (5.5) and (5.7), this implies

$$
\tilde{V}_{1}=\bar{V}
$$

This is the same condition as in Proposition 4.1. It is easy to check, that this level $\tilde{V}_{1}$ can be achieved with a positive level of the period-1 dividend, $\tilde{Z}_{1} \geq 0$, if the capital and dividend constraints are 
satisfied in the discretion equilibrium. Thus, the commitment possibilities are essentially the same as in Proposition 4.1. The central bank can implement the commitment equilibrium and the CPI levels $\tilde{P}_{1}$ and $\tilde{P}_{2}$ by pegging the period-1 price of real consols to $\tilde{P}_{1}^{c}$ and setting its period-1 capital to $\tilde{V}_{1}=\bar{V}$.

Interestingly, it is crucial for the argument that the bond's coupon payment is fixed in real terms. Assume instead that $\rho$ denotes a fixed coupon payment in home currency. Then equation (5.4) is replaced by

$$
P_{t}^{c}=\frac{\rho}{e^{r^{*}+\pi}-1} \quad(t \geq 2)
$$

It follows that the home-currency price of the bond in period 2 is unaffected by monetary policy. Thus, it is impossible for the central bank to peg the nominal price of the bond in period 2 to a level different from the right side of (5.9). The commitment solution can no longer be implemented by pegging $P_{2}^{c}$ to $\tilde{P}_{2}^{c}$.

It is straightforward to see that this result would hold for any asset with returns predetermined in home currency. The price of the asset is equal to the future nominal cash flows discounted by the nominal interest rate $i=r+\pi^{*}$. Balance-sheet management works with foreign-exchange reserves or indexed bonds because, since the future equilibrium is homogenous of degree one in home-currency units, pegging the home-currency price of these assets is equivalent to pegging the home-currency price level, the home-currency value of the CPI. This does not work with fixed-income securities denominated in home currency.

\section{Conclusions}

As we have emphasized above, in a liquidity trap, the nominal interest rate is zero, but the real interest rate is higher than optimal. This causes a recession that is deeper than optimal. The higher-than-optimal real interest rate is due to private-sector expectations of low inflation or even deflation. The optimal policy in this situation must generate expectations of a higher future price level and thereby expectations of higher future inflation. This will lower the real interest rate and stimulate the economy out of the liquidity trap even though the nominal interest rate is zero. The benefit of this is worth overshooting the future inflation or price-level target. The problem is how to make the higher future price level credible. A promise of a higher future price level may not be credible, since the central bank may renege on its promise in the future and achieve a lower price level than promised, so as to maintain low and stable inflation. 
This paper shows that a central bank's realistic concerns about its balance sheet and capital allows it to commit to a higher future price level through a currency depreciation and a crawling peg, in line with Svensson's [19] and [20] Foolproof Way to escape from a liquidity trap. The bank wishes to maintain its independence from the government. A negative capital would require a capital injection and put the bank at the government's mercy. In order to avoid this, the bank never voluntarily allows its capital to fall below a certain minimum level. Because undoing the current currency depreciation by a future currency appreciation would imply a future capital loss on the bank's foreign-exchange reserves, a minimum capital level provides a lower bound on the future exchange rate (an upper bound on the future currency appreciation). By managing its capital such that the minimum capital level is reached for the exchange-rate level consistent with the desired higher future price level, the bank can commit itself to the appropriate exchange-rate path and thereby to the appropriate higher future price level. This kind of commitment mechanism is also possible, if the central bank' holds other assets then foreign-exchange reserves, but not if it holds only fixed-income securities nominated in home currency.

To conclude on a more general note, this paper might contribute to draw the attention of scholars to the balance sheet concerns of central bankers and their implications for monetary policy. These concerns have not been analyzed in the academic literature, although central bankers do seem to care about their balance sheets in the real world. This omission may not be a serious one when central bankers' balance sheet concerns do not significantly influence monetary policy and can be safely ignored to a first approximation. However, there are situations - and a liquidity trap is an important example - where central bankers' balance sheet concerns might matter in a nontrivial way for monetary policy-making. This observation would seem to warrant more theoretical and empirical research on the foundations of central bankers' balance sheet concerns and on their implication for monetary policy. 


\section{Appendix}

\section{A. First-order conditions}

The Lagrangian for the household's optimization problem is

$$
\begin{array}{r}
\mathcal{L}_{t}=\mathrm{E}_{t} \sum_{\tau=0}^{\infty} \delta^{\tau}\left[(1-\alpha) \ln C_{h, t+\tau}+\alpha \ln C_{f, t+\tau}+U\left(\frac{M_{t+\tau}}{P_{h, t+\tau}}\right)-N_{t+\tau}\right. \\
+\theta_{t+\tau}\left(\Pi_{t+\tau}+W_{t+\tau} N_{t+\tau}+M_{t+\tau-1}+e^{i_{t+\tau-1}} B_{t+\tau-1}+S_{t+\tau} e^{r^{*}} B_{t+\tau-1}^{*}+Z_{t+\tau}\right. \\
\left.\left.\quad-P_{h, t+\tau} C_{h, t+\tau}-S_{t+\tau} C_{f, t+\tau}-M_{t+\tau}-B_{t+\tau}-S_{t+\tau} B_{t+\tau}^{*}\right)\right],
\end{array}
$$

where $\Pi_{t} \equiv \int_{0}^{1}\left[P_{h t}(\iota) Y_{t}(\iota)-W_{t} N_{t}(\iota)\right] d \iota$. The first-order conditions are, for consumption,

$$
\begin{aligned}
\frac{1-\alpha}{C_{h t}} & =\theta_{t} P_{h t} \\
\frac{\alpha}{C_{f t}} & =\theta_{t} S_{t}
\end{aligned}
$$

for money,

$$
U^{\prime}\left(\frac{M_{t}}{P_{h t}}\right) \frac{1}{P_{h t}}=\theta_{t}-\delta \mathrm{E}_{t} \theta_{t+1}
$$

for labor,

$$
\theta_{t} W_{t}=1
$$

for foreign-currency bonds,

$$
\theta_{t} S_{t}=\delta e^{r^{*}} \mathrm{E}_{t} \theta_{t+1} S_{t+1}
$$

implying (2.10); and for home-currency bonds,

$$
\theta_{t}=\delta e^{i_{t}} \mathrm{E}_{t} \theta_{t+1}
$$

implying (using the first-order condition for foreign-currency bonds and $\delta e^{r^{*}}=1$ )

$$
e^{i_{t}}=e^{r^{*}} \frac{\mathrm{E}_{t} \theta_{t+1} S_{t+1}}{\mathrm{E}_{t} \theta_{t+1} S_{t}}
$$

the interest-parity condition.

From the first-order condition for money, home-good consumption and home-currency bonds, we get

$$
U^{\prime}\left(\frac{M_{t}}{P_{h t}}\right)=\frac{1-\alpha}{C_{h t}}\left(1-e^{-i_{t}}\right)
$$

which by the assumptions on the liquidity-services function and (2.8) can be written in reduced form as (2.24). 


\section{B. Derivation of equation (2.12)}

The expected utility value of firm $\iota$ 's profits is given by

$$
\left.\left.\mathrm{E}_{t} \frac{1}{P_{h, t+1} Y_{t+1}}\left[P_{h, t+1}(\iota)-\frac{W_{t+1}}{A_{t+1}}\right)\right] Y_{t+1}(\iota)=\mathrm{E}_{t} \frac{1}{P_{h, t+1} Y_{t+1}}\left[P_{h, t+1}(\iota)-\frac{W_{t+1}}{A_{t+1}}\right)\right] Y_{t+1}\left(\frac{P_{h, t+1}(\iota)}{P_{h, t+1}}\right)^{-\xi},
$$

where we have used (2.4). The first-order condition with respect to $P_{h, t+1}(\iota)$ is

$$
\begin{aligned}
0 & =\mathrm{E}_{t} \frac{1}{P_{h, t+1} Y_{t+1}}\left\{Y_{t+1}(\iota)+\left[P_{h, t+1}(\iota)-\frac{W_{t+1}}{A_{t+1}}\right] Y_{t}(-\xi)\left(\frac{P_{h, t+1}(\iota)}{P_{h, t+1}}\right)^{-\xi-1} \frac{1}{P_{h, t+1}}\right\} \\
& =\mathrm{E}_{t} \frac{1}{P_{h, t+1} Y_{t+1}}\left\{Y_{t+1}(\iota)+\left[P_{h, t+1}(\iota)-\frac{W_{t+1}}{A_{t+1}}\right](-\xi) Y_{t+1}(\iota) \frac{1}{P_{h, t+1}(\iota)}\right\} \\
& \left.=\mathrm{E}_{t} \frac{1}{P_{h, t+1} Y_{t+1}}\left\{(1-\xi)+\xi \frac{W_{t+1}}{A_{t+1}} \frac{1}{P_{h, t+1}(\iota)}\right] Y_{t+1}(\iota)\right\} .
\end{aligned}
$$

This, together with $P_{h, t+1}(\iota)=P_{h, t+1}$ gives

$$
P_{h, t+1}(\iota)=\frac{\xi}{\xi-1} \frac{\mathrm{E}_{t} \frac{1}{P_{h, t+1} Y_{t+1}} \frac{W_{t+1}}{A_{t+1}} Y_{t+1}(\iota)}{\mathrm{E}_{t} \frac{1}{P_{h, t+1} Y_{t+1}} Y_{t+1}(\iota)} .
$$

We realize that all firms $\iota \in[0,1]$ will set the same price $P_{h, t+1}(\iota)$ and produce the same quantity $Y_{t+1}(\iota)$, so by $(2.2)$ and $(2.3)$ we have $P_{h, t+1}(\iota)=P_{h, t+1}$ and $Y_{t+1}(\iota)=Y_{t+1}$ for all $\iota \in[0,1]$. Using this, (2.8) and the fact that $P_{h, t+1}$ will be predetermined and known in period $t$, the price-setting equation can be written as (2.12).

\section{Households and firms perceiving a positive probability of a liquidity trap}

Assume that private agents correctly perceive that the fall in log productivity, $b$, or equivalently the period 1 natural real interest rate $\bar{r}_{1}$, will be drawn from a probability distribution. For convenience we define the probability distribution in terms of $\bar{r}_{1}$ rather than $b$, and denote its density function by $f\left(\bar{r}_{1}\right)$. Private agents know $f\left(\bar{r}_{1}\right)$ and form their expectations rationally.

Until period 0 and from period 2 onwards, the economy is in the steady states that we have already analyzed in the text. In period 1, the Phillips curve (2.36) can be written

$$
\pi_{1}=\left(\alpha \bar{q}-q_{0}\right)+\Delta p_{h 1}+\alpha\left(y_{1}-\bar{y}\right)
$$

where $\Delta p_{h 1} \equiv p_{h 1}-p_{h 0}$ and we use that $p_{0}=\alpha q_{0}+p_{h 0}$. Since $q_{0}=\bar{q}$, this becomes

$$
\pi_{1}-\Delta p_{h 1}=\alpha\left(y_{1}-\bar{y}\right)
$$

For period 0, we can no longer assume that intermediate-good producers preset prices for period 1 such that $\Delta p_{h 1}=\pi$. These producers realize that the economy might with some probability be 
in a liquidity trap in period 1 , in which case the realized inflation rate will be lower than $\pi$. As a consequence, $\Delta p_{h 1}$ will not equal $\pi$ but be lower than $\pi$. It will be the solution to a fixed-point problem that we specify below.

Price setters do not know for sure, in period 0 , whether the economy will be in a liquidity trap in period 1 . The economy will be in a liquidity trap in period 1 if the fall in expected productivity growth, $b$, is above a threshold, or, equivalently, if the natural interest rates, $\bar{r}_{1}$, falls below a threshold (both thresholds are endogenously determined in equilibrium). If the economy is in a liquidity trap, the output gap is given by the binding constraint (2.35) with $\pi_{2}=\pi$

$$
y_{1}-\bar{y}=\frac{1}{1-\alpha}\left(\bar{r}_{1}+\pi\right) .
$$

If the economy is not in a liquidity trap, the output gap can be computed by eliminating $\pi_{1}$ from (C.1) and (2.34). This gives

$$
y_{1}-\bar{y}=\frac{\alpha}{\lambda+\alpha^{2}}\left(\pi-\Delta p_{h 1}\right)
$$

The equilibrium output gap is the minimum of these two expressions

$$
y_{1}-\bar{y}=\min \left(\frac{1}{1-\alpha}\left(\bar{r}_{1}+\pi\right), \frac{\alpha}{\lambda+\alpha^{2}}\left(\pi-\Delta p_{h 1}\right)\right) .
$$

Equation (2.16) for $t=1$ can be written in logs as

$$
\mathrm{E}_{0} \exp \left(y_{1}-\bar{y}\right)=1
$$

that is,

$$
\int_{-\infty}^{\infty} \exp \left[\min \left(\frac{1}{1-\alpha}\left(\bar{r}_{1}+\pi\right), \frac{\alpha}{\lambda+\alpha^{2}}\left(\pi-\Delta p_{h 1}\right)\right)\right] f\left(\bar{r}_{1}\right) d \bar{r}_{1}=1 .
$$

The equilibrium level of $\Delta p_{h 1}$ is the solution to this equation. In equilibrium, the economy falls into the liquidity trap if and only if the natural rate of interest rate falls below the level, denoted $r$, for which the two terms under the minimum are equal. This level is given by

$$
r=-\pi+\frac{\alpha(1-\alpha)}{\lambda+\alpha^{2}}\left(\pi-\Delta p_{h 1}\right)
$$

Note that $r>-\pi$ for $\Delta p_{h 1}<\pi$, so the fact that the liquidity trap is expected with some probability makes the liquidity trap happen more often. The threshold $r$ for the natural interest rate corresponds to a threshold for $b$.

Note that equation (C.3) does not necessarily have a solution. In particular, a solution exists only if the probability of a liquidity trap is not too large. 
To see this, assume that private agents know with certainty that the natural real interest rate will fall to a level $\bar{r}_{1}<-\pi$. Then the minimum term on the left side of (C.3) is always strictly negative, implying that the integral cannot be equal to 1 . There is no equilibrium in this case. To take a more specific example that nests the assumption made in the main text, assume that expected fall in productivity growth, $b$, is binomially distributed, with a positive value resulting in $\bar{r}_{1}<-\pi$ with probability $\gamma$ and a zero value resulting in $\bar{r}_{1}=r^{*}$ with probability $1-\gamma$. Then it is not difficult to see that equation (C.3) has a solution - and an equilibrium exists - if and only if the probability of an expected fall in productivity growth, $\gamma$, is not too large. In the main text, we considered the limit case where this probability is infinitesimally small. In this case the solution is $\Delta p_{h 1}=\pi \cdot{ }^{14}$

Conditional on these changes, the analysis presented in the main text remains essentially the same. The period-1 relationships remain (2.35) and (2.36), with $\pi$ in (2.36) replaced by the level of $\Delta p_{h 1}$ that satisfies (C.3). This complicates the algebra somewhat, but the discretion and commitment equilibria, as well as the impact of the central banker's balance-sheet concerns, can be derived following the same steps as in sections $2.5,2.6$, and 4 .

\section{Central-bank assets including domestic credit}

With domestic credit, $D_{t} \geq 0$, on the central bank's balance sheet, we have to modify the domestic bond market equilibrium, (2.7), to be

$$
B_{t}+D_{t}=0
$$

(in which case the central bank holds privately issued bonds), or modify the government's budget constraint to include bonds issued, interest on outstanding bounds, net transfers to the private sector, and the dividend received from the central bank. The central bank's balance sheet, (2.6), is modified to

$$
Z_{t}+S_{t} R_{t}+D_{t}=M_{t}-M_{t-1}+S_{t} e^{r^{*}} R_{t-1}+e^{i_{t-1}} D_{t-1}
$$

and the central bank's capital is given by

$$
V_{t} \equiv S_{t} R_{t}+D_{t}-M_{t} \geq \bar{V} \geq 0
$$

\footnotetext{
${ }^{14}$ The nonexistence of equilibrium with a sufficiently high probability of a liquidity trap is related to the observation that monetary policy that keeps inflation expectations low may prevent an equilibrium also under flexible prices. As noted in footnote 4, the assumption of constant money supply is sufficient to ensure that no liquidity trap arises under flexible prices. With a constant future money supply, the future price level is exogenous. With flexible prices, a present negative output gap and hence a positive real interest-rate gap cause the present price level to fall. This increases expected inflation, reduces the interest-rate gap and increases the output gap. The present price level falls until the output and interest-rate gaps are zero. It follows that monetary policy that prevents inflation expectations from rising may prevent a flex-price equilibrium with a low natural interest rate.
} 
which, using the first equation, can be rewritten:

$$
V_{t}=S_{t} e^{r^{*}} R_{t-1}+e^{i_{t-1}} D_{t-1}-M_{t-1}-Z_{t} \geq \bar{V} \geq 0
$$

It follows that, if the central bank does not distribute any dividend in period 2 and the economy was in a liquidity trap in period $1\left(i_{1}=0\right)$, the period-2 exchange rate satisfies

$$
S_{2} \geq \frac{M_{1}-D_{1}+\bar{V}}{e^{r^{*}} R_{1}},
$$

which generalizes (4.7). The lower bound on the right-hand-side must be equal to $\tilde{S}_{2}$, which is the case if the period-2 level of central bank capital $\tilde{V}_{2}=\tilde{S}_{2} e^{r^{*}} R_{1}+D_{1}-M_{1}$ is equal to $\bar{V}$. So it remains true that the central bank must set its capital at the minimum level $\bar{V}$ to implement the commitment exchange rate in period 2. To see the implication for the period 1 dividend policy, using (D.1) and (D.2), we note that

$$
V_{2}=V_{1}+\left(e^{i_{1}}-1\right)\left(S_{1} R_{1}+D_{1}\right)-Z_{2}
$$

which, together with $i_{1}=0$ and $Z_{2}=0$, implies that $V_{1}$ must be equal to $\bar{V}$, too. As in the case with no domestic credit, we can then demonstrate that it is possible to choose a non-negative dividend $Z_{1}$ in period 1 so as to set $V_{1}$ equal to $\bar{V}$ by using the assumption that the central bank's capital is above the minimum under discretion $\left(\hat{V}_{1} \geq \bar{V}\right)$. The levels of $R_{1}$ and $D_{1}$ are not unique in the optimal policy. However, there must be a strictly positive level of reserves, otherwise the constraint $V_{1} \geq \bar{V}$ would not involve the exchange rate (we cannot write equation (D.3) if $R_{1}=0$ ). It follows that the presence of domestic credit does not affect the commitment mechanism as long as there is a strictly positive level of reserves. 


\section{References}

[1] Aghion, Philippe, Philippe Bacchetta and Abhijit Banerjee (2001), "Currency Crises and Monetary Policy in an Economy with Credit Constraints," European Economic Review 45, 11211150.

[2] Auerbach, Alan J., and Maurice Obstfeld (2003), "The Case for Open-Market Purchases in a Liquidity Trap," NBER Working Paper No. 9814.

[3] Bernanke, Ben S. (2003), "Some Thoughts on Monetary Policy in Japan," speech on May 31, 2003, www.frb.gov.

[4] Cargill, Thomas F. (2004), "Price Stability, Capital Structure, and Bank of Japan Policy," working paper, University of Nevada.

[5] Eggertsson, Gauti (2003), "How to Fight Deflation in a Liquidity Trap: Committing to Being Irresponsible," IMF Working Paper WP/03/64.

[6] Eggertsson, Gauti, and Michael Woodford (2003), "The Zero Bound on Interest Rates and Optimal Policy," Brookings Papers on Economic Activity 1:2003, 139-233.

[7] Ernhagen, Tomas, Magnus Vesterlund, and Staffan Viotti (2002), "How Much Equity Does a Central Bank Need?" Sveriges Riksbank Economic Review 2002:2, 5-18.

[8] Fukui, Toshihiko (2003), "Challenges for Monetary Policy in Japan," speech on June 1, 2003, www.boj.or.jp/en/press/03/ko0306a.htm.

[9] Grilli, Vittorio (1986), "Buying and Selling Attacks on Fixed Exchange Rate Systems," Journal of International Economics 20, 143-156.

[10] Hawkins, John (2003), "Central Bank Balance Sheets and Fiscal Operations," in Fiscal Issues and Central Banking in Emerging Economies, BIS Papers No.20, Bank for International Settlements, Basel.

[11] Isard, Peter (1994), "Realignment Expectations, Forward Rate Bias, and Sterilized Intervention in an Optimizing Model of Exchange Rate Adjustment," International Monetary Fund Staff Papers 41,435-59. 
[12] Krugman, Paul (1998), "It's Baaack! Japan's Slump and the Return of the Liquidity Trap," Brookings Papers on Economic Activity 2:1998, 137-87.

[13] Leone, Alfredo M. (1994), "Institutional and Operational Aspects of Central Bank Losses," in Balino, Tomas J.T., and Carlo Cottarelli, eds., Frameworks for Monetary Stability: Policy Issues and Country Experience, IMF, Washington, D.C., 738-755.

[14] Pringle, Robert (2003), "Why Central Banks Need Capital," Central Banking 14:1, 76-80.

[15] Vaez-Zadeh, Reza (1991), "Implications and Remedies of Central Bank Losses," in Downes, Patrick, and Reza Vaez-Zadeh, eds., The Evolving Role of Central Banks, IMF, Washington, D.C., 69-92.

[16] Sims, Christopher (2001), "Fiscal Aspects of Central Bank Independence," working paper, www.princeton.edu/ $\sim \operatorname{sims.}$

[17] Stella, Peter (1997), "Do Central Banks Need Capital?" IMF Working Paper WP/97/83.

[18] Stella, Peter (2002), "Central Bank Financial Strength, Transparency, and Policy Credibility," IMF Working Paper WP/02/137.

[19] Svensson, Lars E.O. (2001), "The Zero Bound in an Open-Economy: A Foolproof Way of Escaping from a Liquidity Trap", Monetary and Economic Studies 19(S-1), Bank of Japan, $277-312$.

[20] Svensson, Lars E.O. (2003a), "Escaping from a Liquidity Trap and Deflation: The Foolproof Way and Others," Journal of Economic Perspectives 17-4, 145-166.

[21] Svensson, Lars E.O. (2003b), "The Magic of the Exchange Rate: Optimal Escape from a Liquidity Trap in Small and Large Open Economies," working paper, www.princeton.edu/ svensson.

[22] Zhu, Feng (2004), "Central Bank Balance Sheet Concerns, Monetary and Fiscal Rules, and Macroeconomic Stability," working paper, pantheon.yale.edu/ fz9. 